\title{
Serious gaming as an innovative means for handling complexity in flood risk reduction
}

\author{
Frank den Heijer ${ }^{1, a}$, Jeroen S. Rijke ${ }^{1}$ and Maria Barciela Rial ${ }^{1}$ \\ ${ }^{1}$ HAN University of Applied Sciences, Sustainable River Management Group, Ruitenberglaan 26, 6826 CC, Arnhem, the Netherlands
}

\begin{abstract}
Flood risk reduction has always been vital to the Netherlands. The complexity that flood risk managers are facing has grown over time and is expected to do so due to developments of new knowledge, methods, innovations and data science. To fulfill their statutory responsibility, flood risk managers are urged to make progress reducing flood risk. Uncertainty how to handle the complexity, lack of data and experience to use more complex knowledge, and intransparency of the benefits of the new opportunities and tools, hampers the utilization and implementation of the risk based safety policy. Reflection is therefore needed about the roles and capacities of organizations and individual professionals in the Dutch risk management system. Meanwhile, the scientific literature and educational/training programmes suggest that serious gaming is an effective instrument to support individuals and organisations with dealing with complexity. Therefore, we explore the added value of serious gaming to enhance flood defence asset management in this paper. The objectives are threefold: 1) to identify lessons about dealing with complexity in current asset management practice for flood defence systems; 2) to analyse to which extent serious gaming can be helpful and 3) to develop a set of requirements for a serious game to enhance flood defence asset management in the Netherlands.
\end{abstract}

\section{Introduction}

Serious games receive a lot of attention worldwide, because the games are enablers in motivating players to learn and to change the way they learn (Harteveld \& Bidarra, 2007). Duke \& Geurts (2004) mention "understanding complexity" as one of the goals of serious games, in addition to stimulating creativity, improving communication and reaching a consensus. In recent years, serious games have been emerging for dealing with complexity (den Haan et al. 2016; Meijer 2012; Harteveld 2011; Bekebrede, 2010; Belloti, Bella \& DeGloria, 2010). Among others awareness, training and a shared understanding are the results of playing a serious game. Research has shown that serious games can be used well for combining technical and social complexity (Rijcken et al, 2012; Mayer 2009). Thus, serious games fit well with the complex socio-technical context of water management in the Netherlands.

The outline of the paper is as follows. In Section 2, we give a brief introduction of Flood Risk Management in the Netherlands, the asset management of flood defences and the organisation. Dealing with complexity is introduced in Section 3 including some specific complexities for flood risk management in the Netherlands. Serious gaming as a means to learn to deal with complexity is introduced in Section 4. The project Prometheus, in which the application of serious gaming is explored for flood risk management, is explained in Section 5, together with the emerging requirements for a serious game meeting present challenges of flood risk management in the Netherlands. Section 6 closes this paper with a concluding discussion.

\section{Flood risk management in Netherlands}

\subsection{Flood risk policy - safety standards}

In the Netherlands, dikes have been built from the early middle ages. About $60 \%$ of the Netherlands is flood prone (Figure 1). In former days, the height and construction of dikes were mainly based on experience.

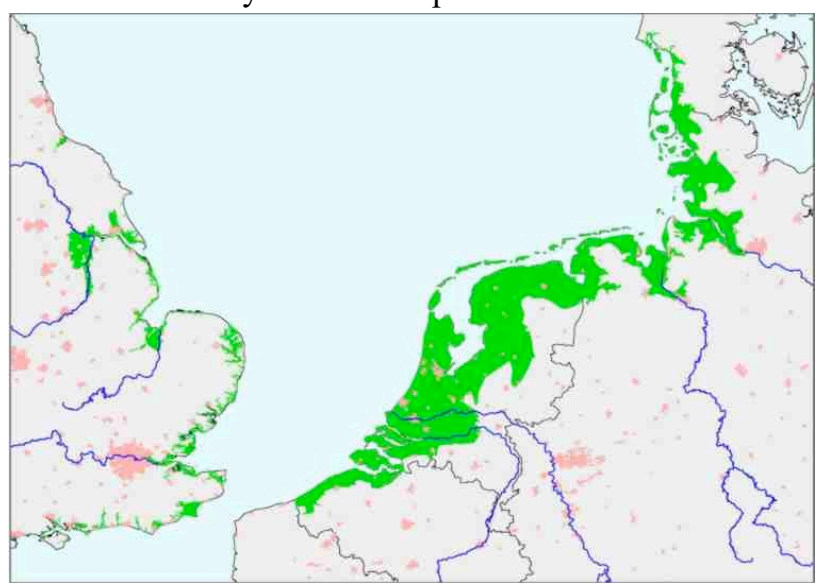

Figure 1. Flood prone areas in the Netherlands, and in other countries in North-West Europe. 
After the disaster in 1953, during which 1836 people died (Slager, 2003), a more scientific and quantitative approach was developed. Safety standards were established based on simplified risk assessments (van Dantzig, 1956). Based on these standards design rules were developed, dikes were strengthened, and storm surge barriers have been built (ICID, 2004). In the Netherlands, about $3500 \mathrm{~km}$ so-called primary flood defences prevent from flooding from sea, relatively large lakes or main rivers. To secure safety of the primary flood defences on the standard level, these levels were established by law since 1996 varying from $1 / 10000$ per year in coastal populated area's to $1 / 1250$ per year for the river area. The standards represented the loads (e.g. water levels, waves) for which each single stretch of the flood defences should be certainly safe. Since 1996, a periodic assessment is also required by law which used to take place each 5 years. The reports represented the probabilities of 'overloading' of the actual status of the flood defences. Referring to the standards the flood defences were 'rejected' or 'approved'.

The initial assessment procedure has been improved with insights in hydraulic boundary conditions, dike strength, dike breach and flooding, allowing to calculate more realistic flood risks. The Dutch Technical AdvisoryCommittee on Water Defences (TAW, at present the Expertise Network Water defence, ENW) proposed in 1993 the preparation of new standards based on improved scientific knowledge of flood defences, breach characteristics and flood risk calculations, and based on new data (TAW, 1997). The safety standards in the Water Act are re-established in 2017 (Staatsblad, 2016). Based on a more realistic and extensive risk assessment, the standards represent the acceptable probability of flooding for trajectories of flood defences. The trajectories are chosen as the total length along which a breach would lead to the same flooded area. The length of these trajectories vary, but most of them are between $20-50 \mathrm{~km}$. The trajectories have a safety standard between $1 / 100$ per year and $1 / 30000$ per year. Only near a nuclear power plant the standard is more stringent. Next to the safety standard for the ultimate acceptable flooding probability, Signal-values for the flooding probability have been given in the Water Act as well (Staatsblad, 2016). The signal-values indicate to start preparations for reinforcements to have them ready to meet the safety standard in time. For most of the ageing flood defences the time between reaching the signal value and the standard is about 15 years. Preparations for reinforcements last mostly 6-8 years, and sometimes additional measurements are needed.

\subsection{National Flood Protection Program (HWBP)}

In the Netherlands, Waterboards are responsible for the actual condition of the flood defences. Before 2008, they applied for budget to reinforce the defences to the regional ministerial agencies. Since 2008, the dike reinforcements are centralised in the National Flood Protection Program (in Dutch abbreviated by HWBP; Staatscourant, 2007). The total dike length to be reinforced is continuously changing. Reinforcements are delivered, and new dikes to be reinforced are upcoming. Furthermore, new knowledge, climate change and new measurements change our view on actual safety. The actual length to be reinforced is 928 km (HWBP, 2020). The new standards (Staatsblad, 2016) are expected to increase the total dike length to-bereinforced because they are more stringent than the old ones, so the dikelength to be reinforced may be expected in the range of 1200-1600 km. Based on the total length of $3500 \mathrm{~km}$ and an average life cycle of 50 years each year about $70 \mathrm{~km}$ should be reinforced, considered on the long run. Last decades the yearly reinforced dike length is far less. HWBP spends about $400 \mathrm{M€} /$ year and the average costs for the reinforcement are about $10 \mathrm{M} € / \mathrm{km}$. The ambition of HWBP is to increase the yearly reinforced dikelength to $50 \mathrm{~km} /$ year, to meet the status 'dike system safe on standard level' before 2050. Therefore HWBP stimulates innovative design to optimize reinforcement costs and dike footprint.

\subsection{Asset management of flood defences}

Asset management is defined as 'the coordinated activities of an organization to realize value from assets. Realization of value will normally involve a balancing of costs, risks, opportunities and performance benefits' (ISO, 2014). In the domain of public infrastructures the value is mostly interpreted as to comply to a certain political decided service level, or to get the best service level for a given budget. Asset management tasks can be divided in strategic, tactic and operational decision levels. As shown in Figure 2 the strategic level is about flood defence policy and focus on long term and flood defence context, the tactic is about prioritization and planning at system level and focus on mid-long term horizon, and the operational level is about actual projects and interventions and focus on the short term (Deltares, 2020). The interconnection between these levels consists of boundary conditions for the tasks on a lower level, or the feedback from the lower level on effects of a strategy or planning.

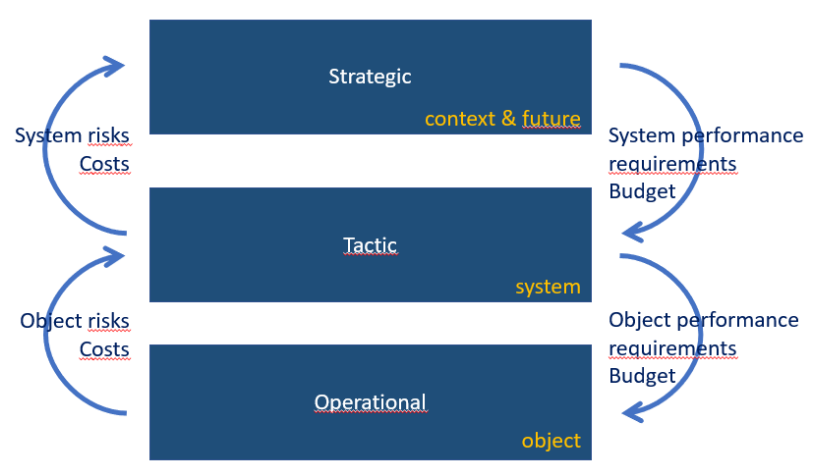

Figure 2. Overview of distinction and consistency of different asset management decision levels.

Asset management of the flood defence system serves to maintain the flood defences on the political decided service level. The asset management required is a particular case because:

- $\quad$ the assets are in public space, safety against flooding is one of the functions; 
- the management is about more than one organisation, even for a single function mostly more organisations are involved;

- $\quad$ the realizations of 'value' means in practice mostly a minimization of investment costs, in stead of balancing risk, cost, opportunities and performance over time;

- The performance of flood defences is (at least for the standards in the Netherlands) almost always invisible;

- The life time is practically end-less. The performance of a dike is ageing because of settlements, or climate change, but the construction material is not ageing

So, flood defences are mostly multi-used (HWBP, 2020), multi-managed and multi-financed (Staatsblad, 2016). This implies that political decisions always needs to have enough support from policy, science and public opinion.

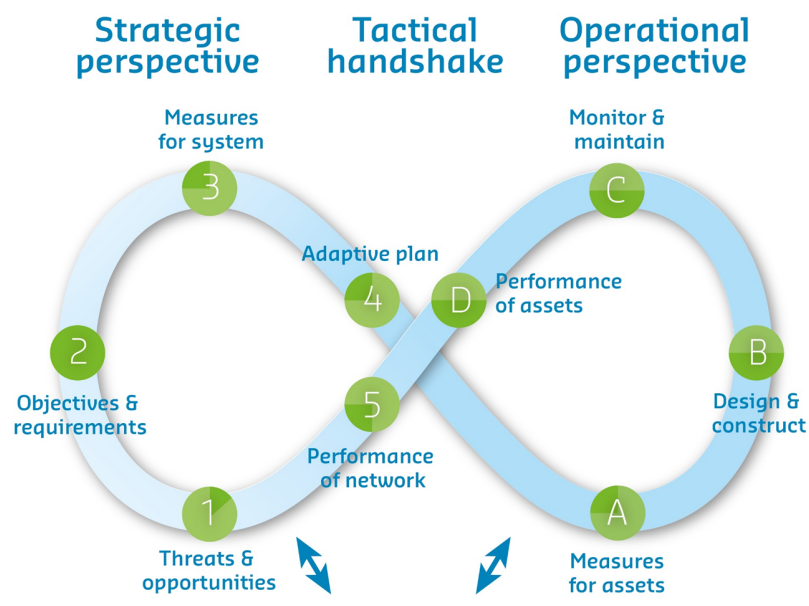

Figure 3. Overview of distinction and consistency of different asset management decision levels (FAIR, 2019).

In the EU project FAIR (Flood infrastructure: Adaptation, Innovation and Resilience) the common scheme of Figure 2 is specified for flood defences, see Figure 3 (FAIR, 2019). It suggests the infinity of the life cycle. The dots 1,2 and 3 on the left express the activities with a strategic character. The dots A, B and C on the right express the activities with an operational character. The dots 4, 5 and $\mathrm{D}$ in the middle express the activities with a tactic character. Both sides of the have a different rhythm, but they are definitely connected. The external factors influencing the decisions in the infinity sign, such as new insights in climate change, are expressed by the arrows at the bottom of the figure.

Asset management often is identified by being 'in control'. Just as often it is unclear what is meant by being 'in control' in the field of flood defence management, since the events are very rare and unpredictable. Asset management of flood defences is meant to maintain the safety against flooding on the political agreed level. Several Waterboard are adopting asset management as a means to be in control and transparent. In (Volker et.al. 2013) 5 levels of maturity are described: ad hoc, repeatable, standard, optimal and managed. In a selfassessment performed in the EU project FAIR, a Waterboard and Rijkswaterstaat (Ministry of Infrastructure and Water Management, from here: the
Ministry) assess their selves as having a maturity of standard to optimal (FAIR, 2020).

\subsection{Organisation of Flood risk management}

From an organisational perspective, asset management of flood defences is complex as well. The size of the projects is rather large, and the different roles and responsibilities, and so the knowledge required for weighing choices, is fragmented within and between organizations (ROBAMCI, 2015). The care for safety against flooding is mainly divided between The Ministry and Waterboards. There are 3 main tasks, with some subtasks, as presented in Figure 4, left column:

- The daily management of the water defences, consists mainly of maintenance and crisis management. The maintenance are a responsibility of the Waterboards. The activities include inspection, monitoring, licencing and management of the revetments. During high water events the Waterboards perform inspection, implementing emergency measures, issuing warnings, crisis communication (ENW, 2017). The Ministry is responsible for flood forecasting and warning. Ministry, Provinces, and Communities are responsible for evacuation.

- The periodic safety assessment. For this, Waterboards gather the required data, perform or outsource the calculations, and report the results to the Ministry. Development of design and assessment rules, together with the tools to perform the calculations, are the responsibility of the Dutch Ministry. The Ministry checks as well whether the waterboards performed the assessments. The results of the assessment are reported to Parliament.

- Reinforcement. The reinforcement is primarily the responsibility of the Waterboards. The subtasks are presented here as the design and actual implementation, however, these can be subdivided as well. Most of the Waterboards outsource large parts of the design to the consultancy market. The implementation is outsourced to contractors, under supervision of the Waterboards.

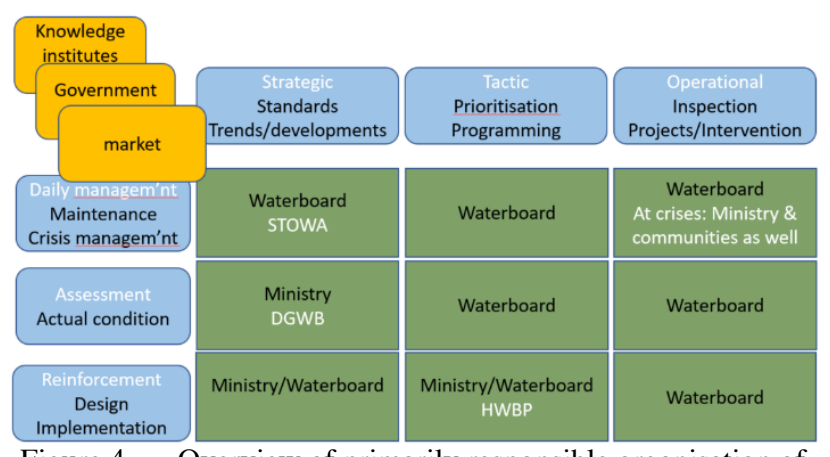

Figure 4. Overview of primarily responsible organisation of flood defence tasks in the Netherlands in a matrix between main tasks (vertical) and decision level (horizontal). STOWA: research institute of the Waterboards, DGWB: part of Ministry.

In the Netherlands, the Waterboards are primarily responsible of the actual condition of the primary flood defences under the supervision of The Ministry. However, 
there are parts of the flood defences under the direct responsibility of the Ministry for the actual condition: dunes, storm surge barriers and connecting flood defences like the Afsluitdijk. In the following we will include this task of the Ministry as well when we mention Waterboards).

The main tasks all have strategic, tactic and operational decision level aspects. For example, the Ministry defines the assessment rules (strategic), the waterboards has to program (tactic), outsource, interpret and submit (operational) the assessments, and the Ministry checks (operational). The cooperation between Waterboard and Ministry becomes most visible in the tactic decisions for reinforcement, when and where to invest. This is a task for the HWBP, an alliance of Ministry and Waterboards.

The responsibilities in the management of the flood defence system is schematized in Figure 4 as a matrix between the main tasks (vertical) and the decision levels (horizontal). The upper row gives examples of types of decisions to be made, such as prioritizing at a tactic level, and the left column gives examples of the main tasks.

As can be seen there is no single organisation responsible for the complete main task, unless the Ministry has the supervision and ultimately the full responsibility. This differs from the organisation in former days (before 1900), when the Waterboards are the single and ultimate responsible organisation. Furthermore, most of the Waterboards has different departments for the 3 main tasks. So the knowledge, data, tools and experience required for flood risk management are fragmented within and between organizations (ROBAMCI, 2015).

The 3 fields in orange in Figure 4 mark the different societal forces which are involved in flood defence. As Waterboards and Ministry are rather task oriented, the Market is project oriented, and the knowledge institutes are knowledge oriented. Projects integrates disciplines and interests, and knowledge integrates experiences and research from different disciplines. Both are able to connect the fields in Figure 4. Waterboards outsource parts of the activities they are responsible for to the market. The Ministry outsources the knowledge development to knowledge institutes as Deltares and Universities. Both Waterboards and Ministry support knowledge development at Universities and Universities of Applied Sciences. So, both the market and the knowledge development institutes are 'connectors' for the different fields in Figure 4.

\section{Complexity and serious gaming}

\subsection{Complexity in large infrastructural projects}

Many definitions and interpretations of complexity exist. Johnsen (2001) defined: Complexity characterises the behaviour of a system or model whose components interact in multiple ways and follow local rules, meaning there is no reasonable higher instruction to define the various possible interactions. Following this definition lead to the assumption that in a complex process, system or model, multiple choices may be made which are not prohibited, based on misunderstanding, or mistakes, and which lead to different outcomes.

Hertogh \& Westerveld (2010) describe complexity from a practitioners view and define to types of complexity which are useful to characterise large infrastructure projects:

detail complexity: the multiplicity and interdependence of stakeholders, products to be delivered and the activities required for this introduce complexity.

- dynamic complexity: complexity due to the selfdirected nature of a developing project and the unpredictability and limited understanding of the same development. Uncertainty in decision-making and the non-linear progress of a project are the characteristics thereof. At the same time, there are external factors and developments that enlarge unpredictability and therefore make project progress and outcomes uncertain.

For the description of complexity from a practitioners view they present 6 characteristics: technical, social, financial organizational, legal, and time (Hertogh \& Westerveld, 2010). Large infrastructural projects are inherently characterised by combinations of these. Dealing with complexity will be important for the management of those projects. Hertogh \& Westerveld (2010) argue that dealing with complexity requires different management styles, as presented in Figure 5.

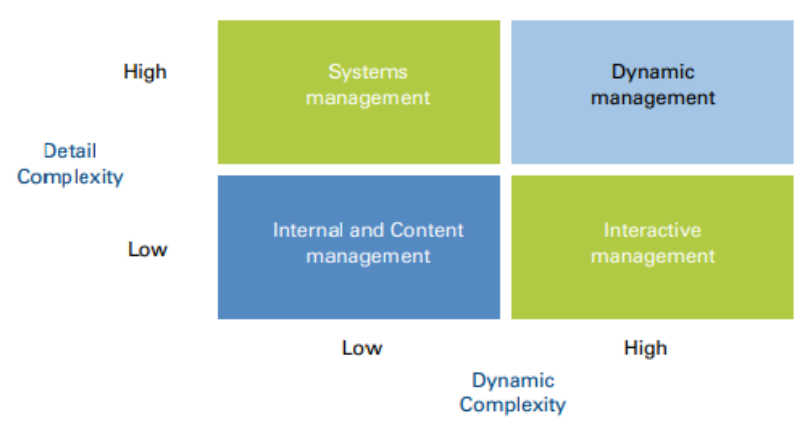

Figure 5. Management strategies for different combinations of complexity in large infrastructural projects (source: Hertogh \& Westerveld, 2010; page 228, Figure 5.9)

\subsection{Complexity in flood risk management}

Worldwide, flood risk management has always been complex because of financial and organisational and social aspects. As presented in section 1 in the flood risk management 'system' several scientific, organisational and social disciplines play a role. The ways of interaction is multiple, and differ dependent on regional and local characteristics and may differ over time. The 'instruction' is abstract formulated so multiple interactions fit in the rules. So the 'system' of flood risk management complies the character of complexity described by Johnson (2001). Flood risk management has to deal with the 6 characteristics and 2 types of complexity for large infrastructural projects by (Hertogh \& Westerveld, 2010). Furthermore: flood risk management is even more than a large infrastructural project, it is a never ending multiused, multi-managed and multi-financed programme, 
which is of existential value for a country like the Netherlands. Several developments increase complexity:

- Technical: in the Netherlands the stringent safety standards and the associated technical approach after the disaster of 1953 increased technical complexity in the second half of the last century. The application of the recently renewed safety standards for flooding probabilities per dike trajectory are technical even more complex than the 'old' ones based on loads per dike stretch. The determination of probabilities of flooding is far more complex than the determination of the probabilities of 'overloading'. Furthermore, the specific data and expertise which are required to carry out the assessments, are not in all cases available.

- Social: although the standards are economic optimal, its implications on reinforcement works is hard to understand for most of the citizens. Most of them never experienced the threat of flooding, and will not as well. Making space and reservation of budget for such an event will conflict with other interest they experience on a daily basis.

- Organisational: HWBP has the challenge to take care for the asset portfolio status 'dike system safe on standard level' in the year 2050. The reinforced dike length per year has to increase significantly to meet that challenge (par. 1.2). Due to the fact the reinforcement is paid with public money, and in public space, the contracting, design and other preparations had to be thorough and transparent. The pressure on HWBP-projects, carried out by the Waterboards, is to be thorough, innovative and as quick as possible.

- Social/organisational: the complexity of the knowledge, organization and processes, combined with a tight time schedule and competitive contracting, stimulates the habit to do the same as before the introduction of new standards and rules. Together with the relatively new standards and design rules, it doesn't invite to use innovative (but uncertain) designs or approaches, even when they could offer much more benefits than the traditional ones. Furthermore, due to the fact sufficient budgets are available the market isn't forced to innovate.

- Environmental/social: with the emerging Environment Act, the government wants to simplify and merge spatial development rules. For the field of Flood defence this implies the use of the space, based on very rare events, and uncertain technical knowledge and data, has to be deliberated with other functions. The stakeholders, organisations as well as citizens, become more assertive. Since different technical alternatives use different space, the debate around space can easily intensify.

Technical: data and IT possibilities increase. This implies that these are managed, used for communication, more and extensive calculations for alternatives, etc. Consequently, Waterboards have to interpret more and more diverse sources of information. The more choices are to be made the less clear will be what are the optimal set of choices.
Al these examples point to an increase of complexity of the already complex flood risk management system in the Netherlands.

\subsection{Dynamic management}

As pointed out in paragraph 2.3 the detailed complexity of flood risk management increases as well as the dynamic complexity. In the model of (Hertogh \& Westerveld, 2010) figured out in Figure 5 this would imply to use a dynamic management model. The Delta Commission (2008) introduced the concept of adaptive policy, which can be seen as the dynamic management on a longer time scale. However, concretisation of this policy in the 3 main present day tasks for flood defences is required. The actual trend to deal with flood risk management complexity is:

- To decrease detail complexity. The Ministry simplifies technical complexity by standard approaches and guidelines. Ministry and Waterboards simplify organisational complexity by (actively or passively) dividing responsibilities in subtasks.

- To decrease interactive complexity. Due to the fact that flood risk management is endless, stability and control are highly valuated. However, the political attention is driven by the occurrence of disasters (RIVM, 2004). Attention moderates in times without disasters. In (RIVM, 2004) these periods are qualified as essential for scientific preparations of policy options. They make quick political decisions possible after a disaster. These times are mostly only a few month (RIVM, 2004). Development of these options, e.g. options for large sea level rise scenarios, need interactive management to lead to feasible options. Thus, the desire for stability is in contradiction to the preparation of options for political windows of opportunity.

Thus, despite the fact that an adaptive policy is proposed, the flood risk management system in the Netherlands is not unambiguous dynamic dealing with complexity, and the trend isn't as well. An important question is how to cope with the increasing complexity. Hertogh \& Westerveld (2010) describe 5 success factors which are important for dynamic management. We cite them in the list below by quotation marks:

'A higher order of co-operation can enable the stakeholder system to deliver outstanding results'; project champions: 'In order to manage complexity [..] successfully, the project initiators need to 'go the extra mile' in the sense that they should feel responsible for delivering project outputs that fit the needs of the involved stakeholders and not only focussing on their constraints in terms of budget and schedule.'

- Competent people: 'Competent individuals make all the difference in the management of complexity'

- Capability to find unique management solutions: 'successful management approaches [..] need to be tailored to the unique character of the project - its context, its history and the unique events associated with it. 
- Windows of opportunity: 'timing of interventions is crucial. Windows of opportunity open as the result of external change events or as the result of re-evaluation of past decisions - or a combination of both.'

So, for a dynamic managed flood risk management system these success factors has to be stimulated. Three of them may be addressed by serious gaming: a higher level of cooperation, competent people, and capacity to find unique management solutions.

\section{Serious gaming}

\subsection{Learning by Serious gaming}

Serious games have many different forms such as digital games, board games, card games, and simulations. A serious game consists of three components, which together ensure that the game is playable, realistic and educational. Harteveld (2011) describes the three components as 'domains'. He distinguishes the domains "reality", "meaning" and "game". In the "reality" domain, the connection between the "real world" and the game is made, creating a representation of reality. Of course this should be a selective representation, to keep the game playable. However, playing the game should give the impression of being busy with the real world. The "meaning" domain gives the game value to the players: which lessons can be learned and what is the meaning of the game for the player? The domain "game" forms the connection between playability and reality: the serious game must at the same time reflect reality, but within the framework of a game concept with rules, strategies and fun. To develop a playable game where the predetermined goals of the game are achieved, a balance must be found between these domains.

Three different types of learning play a role within the domain "meaning" (Baird et al, 2014):

- Cognitive learning, related to the acquisition or restructuration of knowledge.

- Normative learning, which concerns a shift in viewpoints, values or paradigms.

- Relational learning, referring to an improved understanding of others' mind-sets, enhanced trust and ability to cooperate.

Furthermore, the context for effective learning for adults is changing from a traditional context (classroom, student-teacher interaction) to a "hands-on" and "learning on the job" context (Schwandt, 2005). Serious gaming is a good example of a way to do hands-on learning, as the game usually fits in with the daily practice of the player's field of work. Serious games, and specifically role-playing games, are very suitable for achieving a joint learning process (Mayer, 2009; Pahl-Wostl, 2007), and various scientific studies have also shown that a serious game has joint learning as an effect (Hummel et al. 2011; Duijn et al. 2003; Barreteau et al, 2001). The games are based on the principle of "learning-by-doing", with an important "trial-and-error" component (Hummel et al. 2011).

\subsection{Examples of serious games and objectives}

Some examples of the many available games, are ordered below in two types and four objectives. The two types are digital and analogue games. The four objectives are technical understanding, social/organisational understanding, process understanding, and vision development:

Digital, technical understanding. Up to now there are mainly digital serious games for the context of water management in the Netherlands (such as the Dijkpatrouille game, the Sustainable Delta game, STORM role play, SimDelta and Virtual River game; den Haan et al. 2016). The games are played via a computer, in a digital environment, in which models simulate reality to a certain extent and in which action can be taken to achieve certain goals. The games are often focused on issues related to water shortages, floods or spatial planning around rivers.

- Analogue, social understanding. When it comes to bringing different parties closer together, analogue serious games are often used (e.g. Ports of the Future from Deltares, Integrated River Basin Management Citarum from Radboud University Nijmegen, Flood Control Game from FloodCom). The rationale behind this form of play is that the players in an analogue game are not distracted by computer screens and beautiful visualisations and the players as such can better focus on the dialogue between each other.

- Analogue, process understanding. There are a number of simulation games with which the players are trained in work processes of complex projects: PPP game from PPPGroupe, Integrated Project Management game HWBP, simulation Lock Eefde).

- Analogue, vision development. In the context of asset management of Dutch hydraulic structures (e.g. flood barriers and locks), a management game, Deltego, has been developed (Vissers, 2016). This game was used to introduce a new network approach to the various parties involved (asset owner, asset manager, service provider). Instead of a technical object-related approach, there was a need for an integrated approach (with additional complexities). The research came up with the idea of "framing from the top, gaming from the bottom" whereby the frame (the network approach) was spread through a game within the different layers of the organization to support the transition from object approach to integrated approach.

- Digital, vision development. In the project ROBAMCI (Risk and Opportunity Based Asset Management for Critical Infrastructures) a digital serious game has been developed to get the importance of the balance between the performance, risk and cost in the spotlights, as well as predictive analytics for enhanced life cycle management (Deltares, 2020). In Figure 6 the start screen of this game is presented, which shows the possibility to choose for 4 different asset management strategies, and to express a preferred balance in the triangle to minimize costs, maximize performance, or minimize risk. 


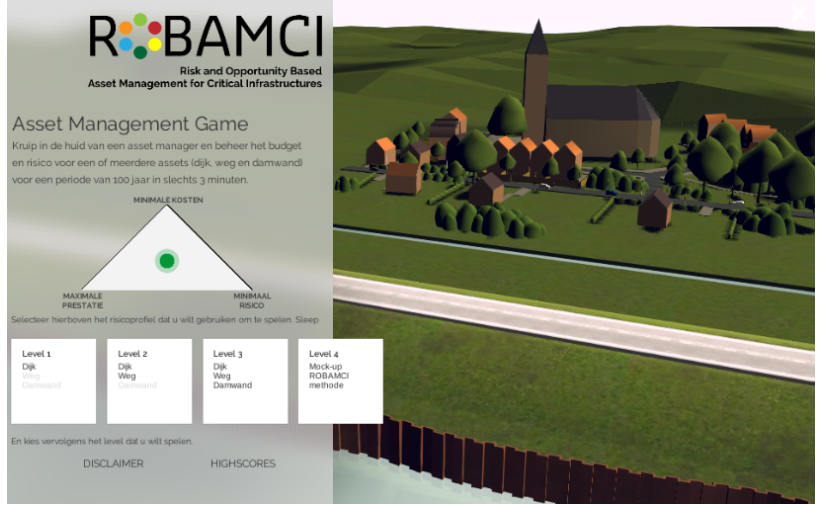

Figure 6. Start screen of the serious game developed in ROBAMCI (www.robamci.nl)

\subsection{Serious game for flood risk management}

Since asset management of dikes is complex from a technical perspective, from a time perspective because of endlessness, and from an social, organisational, legal, financial perspective because dikes are multi-used, multimanaged and multi-financed, serious gaming may be an opportunity. Several bridges has to be build, on all these aspects mentioned in section 2 as characterising complexity, which cannot be crossed over separately.

In former days these bridges are built in practise, between projects, between peers, between generations. In this way a more or less stable knowledge and experience development may lead to safe and sustainable decisions. Since the disaster in 1953 these bridges are build through a national awareness of the need of flood risk reduction. This comes up again during the river floods in 1993 and 1995. Nowadays, the Netherlands has the most safe Delta in the world, the citizens are more assertive and less aware of flood risk, the technical knowledge had increased and is very specialistic. The social and organisational harmony due to the national awareness of flood risk, changes in a more task and project oriented management. The organisational, social and legal aspects are far more important and far more complex than in former days.

In this circumstances the technical basis is changed by the new standards, and the opportunities such as monitoring and innovative implementation techniques are growing. The practise of learning from other projects, between peers, and between generations cannot fulfil the bridge on all these aspects simultaneously.

At present, there is no serious game for flood risk management which covers all the aspects of complexity in its entirety. When the game should meet the requirement of being sufficient realistic, the game would be almost as complicated as reality. A serious game should cover a subset of the reality of asset management of flood defences. In this paper we choose for a serious game to come to a higher level of co-operation between the 3 main tasks or work processes (maintenance, assessment and reinforcement). Application of the serious game may contribute to the second and third success factor mentioned in Section 3.3: competent people, and capacity to find unique management solutions.

\section{Serious gaming to handle complexity}

\subsection{Prometheus}

Project Prometheus aims to contribute to more effective and efficient asset management of dikes. The Prometheus project focuses on improvement and alignment of the different work processes within water boards and The Ministry related to the 3 main flood defence tasks or work processes: maintenance, assessment and reinforcement. In Prometheus 11 partners participate: several Waterboards, the Ministry, an SME, several Universities of Applied Sciences, and Delft University of Technology. HAN University of applied sciences is lead partner.

Serious gaming is used to allow the professionals involved to anticipate to complexity in the work processes and to support them in a joint learning process for more effective and efficient asset management.

The following research question has been formulated: In what way can serious gaming promote knowledge exchange and cooperation over the 3 main tasks or work processes of asset management of dikes?

To answer this question, insight is needed into the complexity that relates to work processes, the way in which knowledge exchange and cooperation takes place (now and ideally) and the added value and limitations of serious gaming. Sub questions to gain this insights are:

- How takes exchange of knowledge place between managers of the 3 main work processes during different management phases of primary flood defences?

- Which dilemmas typically apply during decisionmaking on the work processes of primary flood defences?

- What "best practices" are available for knowledge exchange and cooperation between the professionals in preparation for and during the decision-making?

- How should a serious game be organized to optimally promote knowledge exchange and cooperation between the professionals for the different work processes of asset management of dikes?

- What are the added value and limitations of serious gaming to support knowledge exchange and cooperation for enhanced implementation of asset management for flood defences?

\subsection{Cases}

In Prometheus actual flood risk management issues are raised by the Waterboards. These issues are used to determine typical dilemma's. The serious game has to address these dilemma's, so the terms of reference for the serious game are meant to get this done. The first 6 cases of study are already defined::

- The management of a Vertical Sand-tight Geotextile (in Dutch abbreviated by VZG) near the inner slope to prevent piping (Waterboard WRIJ). This innovative solution consists on the vertical installation of a geotextile behind the dike to prevent sand transport. If the VZG works well, sand transport behind the VZG 
is limited to local sand, which is transported from behind the VZG to ground level. No "pipe" is created under the dike. The question is how to determine over time whether the VZG works well.

- The risk based inspection for beaver activity in dikes (Waterboard WDOD). This case consists on the study of state of the art monitoring and strengthening techniques to reduce the impact of beaver holes in flood defences. Herein, bottlenecks are identified and decision tools are developed.

- A vision for long term monitoring of dikes (Waterboard WSHD). This project aims to develop a vision as a basis for a possible switch from short term project based monitoring to long term, and develop and implement an integral monitoring approach that is transversal to all departments of the water board. In this way, monitoring long term plans can be developed.

- A monitoring plan for dike reinforcement (Waterboard HDSR). This case aims to integrate state-of-the-art techniques in dike monitoring in the decision-making process regarding management, reinforcement and assessment of flood defences. The interaction between technology and governance is the focus point of this case.

- Integral approach of dike trajectories (Waterboard HHNK). This case studies the integration of flood risk reduction measures with spatial developments, (administrative) ambitions and available resources linked to a dike stretch.

- Effect of management choices after 'rejection' of a flood defence (Waterboard WSRL). Many choices are made in the period between the assessment of a dike trajectory and the completion of a reinforcement. Technical choices, environmental choices, organizational choices and process choices all have an influence. WSRL wants to get insight into the influence of choices on the result of the reinforcement.

- Framework of agreements for liquefaction of the flood defences along the Western Scheldt (Waterboard WSSS). This case aims to elaborate the protocol between water board and HWBP with respect to the subsidy for dike reinforcements. The protocol contains the working method, management and maintenance of the border area between flood defence and water bottom / navigation channel (managed by a Waterboard and The Ministry, respectively).

The locations of the cases are presented in Figure 7.

\subsection{Dilemma's}

Dilemma's usually indicates choices of two or more alternatives that are equally unattractive or attractive. They have been present from all times in all fields of interest.

Some dilemma's don't change much over time, other dilemma's come up due to some changes in e.g. knowledge, technology, policy or law. Below some examples will be given of the dilemma's for asset management of the water defences.

First example is the innovative piping prevention by a VZG, the case of WRIJ. The behaviour of a dike with a
VZG is not fully known yet, so the flood risk reduction is not proven. After several model and laboratory studies the ENW advised to construct the VZG for a small dike stretch and to monitor the behaviour of the VZG (ENW, 2017). Waterboard Rivierenland (WSRL) constructed the VZG. HWBP assumed this to be a good example of an innovation and proposed to WRIJ to construct the VZG as well for a small dike stretch. The dilemma for WRIJ is to: - accept a new promising concept without a proven method for design and assessment, but the proof can only to be derived by construction and monitoring; or - construct a traditional dike with a proven and accepted understanding of the safety concept, but which is more expensive and more space consuming.

Serious gaming could be used to get a common understanding of the dilemma, the conditions which has to be fulfilled for the professionals responsible for design, assessment and daily management/maintenance (the 3 main tasks), and the process to fulfil these.

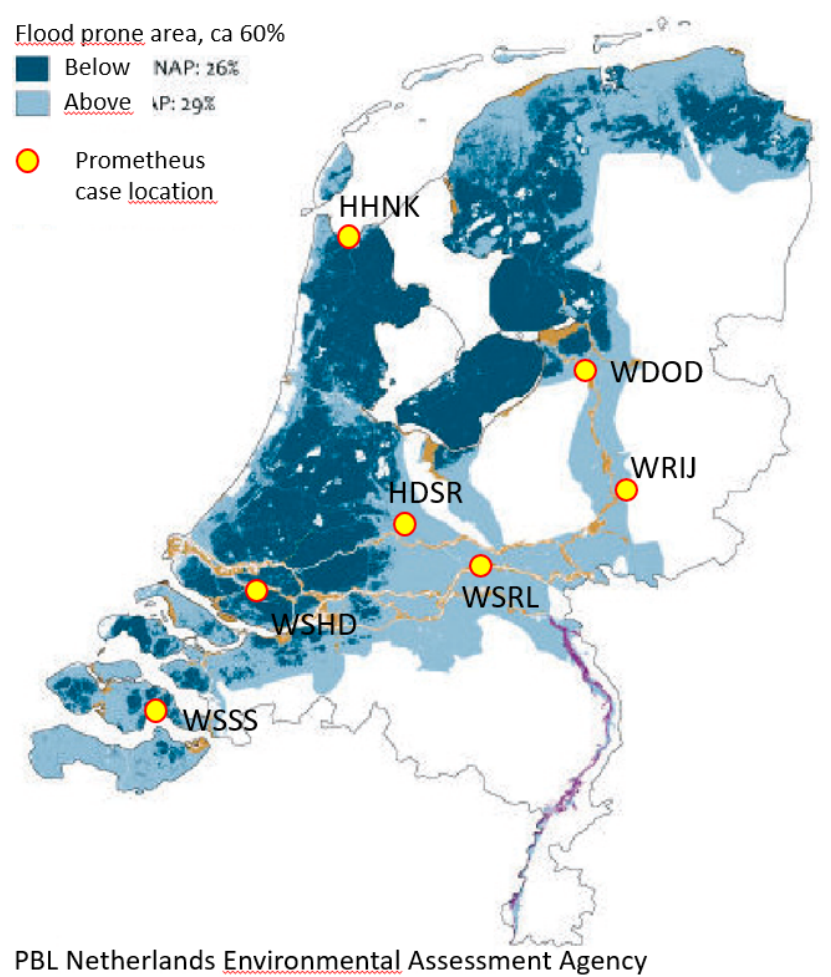

Figure 7. Locations of the cases of Prometheus in the

Netherlands. Between brackets the hosting Waterboards)

Second example is the risk based inspection to beaver activity in dikes, the case of WDOD. Beavers are swimmers and diggers. They may dig their holes in the dikes. Especially during floods, they may dig them because the dikes most likely has dry parts. This undermines the stability. Two problems exist: how to find the holes of the beavers, and how to get them away, because they are a protected species. Both are in principle a task of the water defence management of the Waterboard WDOD. However, for the second they don't have that much possibilities, and the Waterboard is not allowed to fill the hole when the beavers are inside. The waterboard faces the following dilemma regarding the first problem: 
- Inspect very thoroughly and regularly, which is costly, and even in the case they can fill the hole when the beaver is outside, the beaver can return in the neighbourhood; nevertheless, the probability of an unknown beaver holes in the dike during floods will reduce; or

- Inspect sampling in space and time, which is less costly, but the probability of an unknown beaver hole in the dike is larger.

Furthermore, it is important whether the position of a beaver hole in the dike increase the probability of dike failure during floods, and whether the position of a beaver hole along a dike stretch is important for the flood risks. The uncertainties about the behaviour of the beavers, the effect on dike failure probability and risks, and the effectivity of the inspection, hampers the development of a supported strategy. Serious gaming could be used to get a common understanding of the scale of the problem, the risk reduction possibilities, and the process to develop a supported strategy on an effective scale.

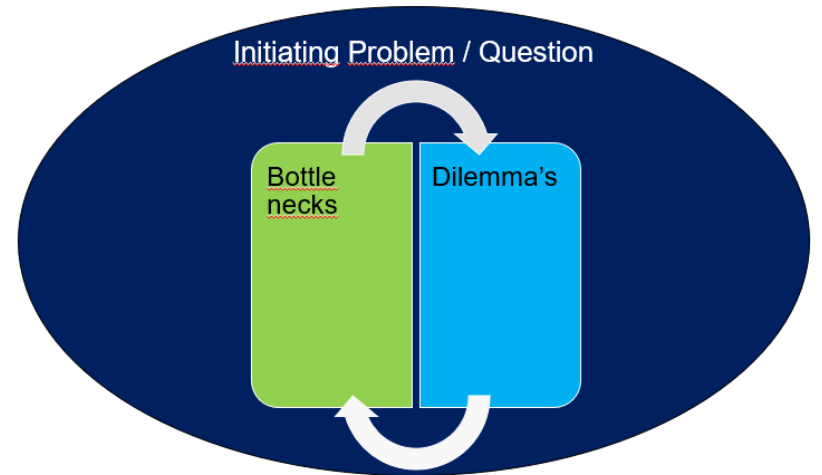

Figure 8. Relation between Initiating problems or questions, bottlenecks and dilemma's

Pending the research through the Prometheus cases we observe a relationship between an upcoming problem or question, initiating bottle necks or dilemma's which may arise, see Figure 8 . The upcoming problem, such as the new safety standards, or an applied assessment leading to a known dike safety on a certain stretch below the standards, may lead to a dilemma or bottle neck. Then the dilemma may lead to a bottle neck or the other way around. Otherwise a dilemma or bottle neck which is not tackled timely may lead to a problem. The different dimensions of these related aspects we observed in the cases are presented in Table 1.

In addition to the hypothesis of section 4 that serious gaming is an effective means to bring cooperation to a higher level, the dimensions of Table 1 lead to the hypothesis that serious games will be helpful to get a better understanding of the interconnection between the presented dimensions in a certain situation.

\begin{tabular}{|c|c|c|}
\hline $\begin{array}{l}\text { Dimension of } \\
\text { probl., dilem- } \\
\text { ma, bottle n. }\end{array}$ & Description & Example \\
\hline Responsibility & $\begin{array}{l}\text { Known or not } \\
\text { known, put expli- } \\
\text { citly down or not }\end{array}$ & $\begin{array}{c}\text { For a department or a } \\
\text { task, for a certain task } \\
\text { or sector/sectors }\end{array}$ \\
\hline Process & $\begin{array}{l}\text { Management of } \\
\text { process }\end{array}$ & $\begin{array}{l}\text { Following the orga- } \\
\text { nisations responsibi- } \\
\text { lities tight or stretchy }\end{array}$ \\
\hline Organisation & $\begin{array}{l}\text { Management of } \\
\text { project, approach } \\
\text { of task }\end{array}$ & $\begin{array}{l}\text { Systematic or } \\
\text { explorative }\end{array}$ \\
\hline Finance & $\begin{array}{c}\text { Degree of } \\
\text { avoiding financial } \\
\text { risks }\end{array}$ & $\begin{array}{l}\text { From the start of an } \\
\text { project/initiative clear } \\
\text { boundaries or not }\end{array}$ \\
\hline Technical & $\begin{array}{l}\text { Degree of innova- } \\
\text { tiveness, ignoran- } \\
\text { ce, or capability }\end{array}$ & $\begin{array}{l}\text { Innovative concepts } \\
\text { with unknown be- } \\
\text { haviour during floods }\end{array}$ \\
\hline Scale & $\begin{array}{l}\text { Scale of scope, } \\
\text { space and time }\end{array}$ & $\begin{array}{c}\text { Scope: sectoral } \\
\text { objective or spatial } \\
\text { quality }\end{array}$ \\
\hline
\end{tabular}

Table 1. Dimensions of Problems, Questions, bottle necks and dilemma's in the cases of Prometheus.

\subsection{Approach to derive Terms of Reference}

With the development of a serious game for the context of flood risk management in the Netherlands in mind, a set of requirements has been set-up. As pointed out in (Aubert et.al., 2019) the 'what', 'why', 'who', and the 'when \& where' has to be addressed.

Firstly the 'what'. The objective of the serious game has to address the present problems and dilemmas in flood defence management, as expressed by the cases in par. 5.2. All address the understanding of impact of choices, in one of the 3 main flood defence tasks. The reason for the cases of Prometheus are almost all based on the intersections of flood defence tasks and levels of decision making, as pointed out in Figure 9, which is more or less the same as the organisational overview of Figure 4. Note there is a connection between daily management and assessment in Figure 9 as well, pointed out by the arrow. Two of the cases address these connection. The position and content of the cases point out that a main problem is the ambiguity with respect to technical or organisational responsibility and accountability.

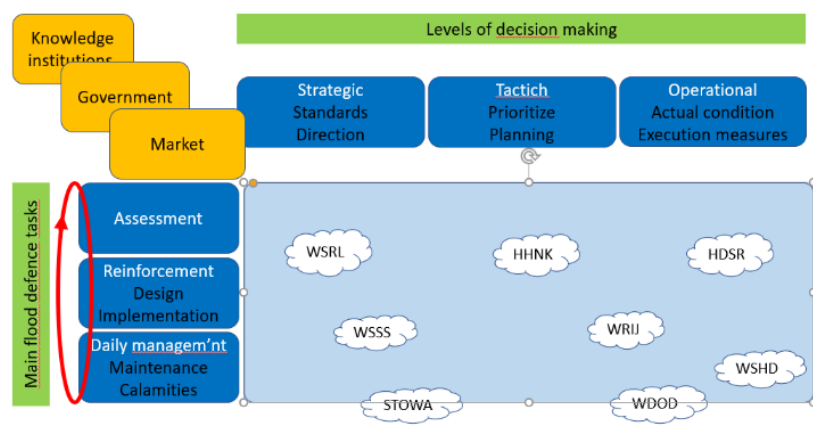

Figure 9. Position of the Prometheus cases in the field of flood defence task and levels of decision making

As pointed out in section 4 serious games should cover the three aspects or domains. They should be realistic, 
meaningful and playable (Harteveld, 2011). Therefore the dimensions of Table 1 can be used to characterise and specify the objective with respect to problem, bottle necks and dilemma's. An overview has to be made of lessons-tobe-learned by playing the game on different decision levels for asset management (see Figure 2 and 9) for education on different levels. Furthermore, the lessons-to-be-learned for professional discussions between technical peers, managers, and cross governance.

Secondly the 'why' to express the purpose of the game. As pointed out in section 3 serious games may be an innovative means for development of dynamic management, especially for 3 of the 5 mentioned success factors. As well they may be a means to increase asset management maturity. In Table 2 some examples are given to increase the capabilities on these 3 success factors for dealing with complexity, here for short called capability dimensions.

\begin{tabular}{|c|l|}
\hline $\begin{array}{c}\text { Capability } \\
\text { dimension }\end{array}$ & \multicolumn{1}{|c|}{ Examples of concrete objectives } \\
\hline $\begin{array}{c}\text { Higher level } \\
\text { cooperation }\end{array}$ & $\begin{array}{l}\text { Improve cooperation in own organisation } \\
\text { Improve cooperation between organisations }\end{array}$ \\
\hline $\begin{array}{c}\text { Competent } \\
\text { people }\end{array}$ & $\begin{array}{l}\text { Increase asset management maturity } \\
\text { Increase understanding of system }\end{array}$ \\
\hline $\begin{array}{c}\text { Capacity to } \\
\text { find unique } \\
\text { solutions }\end{array}$ & Facilitate discussion \\
\hline
\end{tabular}

Table 2. Examples of capability dimensions for the serious games explored in Prometheus.

Thirdly the 'who', expressing the stakeholders participating. The potential players has to be known for who the game should play a role in their education or profession.

Fourth the 'when \& where' expressing the temporal and spatial context of the game. These are interpreted as the conditions for application. In this category are requirements on playtime (depending on the objective), play format (digital or analogue), competitiveness, levels of difficulty etc.

\section{Concluding discussion}

Flood risk management have been complex in the past due to technical, organisation and financial dimensions, and becomes more complex due to increasing technical, organisational, legal and social complexity. An adaptive policy is proposed on a strategic level, but the operational flood risk management system in the Netherlands is not unambiguous dynamic dealing with complexity. The lessons to deal with complexity in flood defence asset management are to strive for a higher level of cooperation, to get competent people and to develop the capacity to find unique solutions.

Serious games, and specifically role-playing games, are very suitable for achieving a joint learning process (Mayer, 2009; Pahl-Wostl 2007). Learning can be stimulated on cognitive, normative and relational level. This fits well to the lessons how to deal with increasing complexity on technical, organisational and social levels. Serious gaming can particularly be an effective instrument if it is applied in a setting that involves multiple asset management roles across the different main tasks of flood defence management. Serious gaming can offer a means for better alignment between these tasks, because the taskmanagers are encouraged in a simulated environment to share knowledge in order to achieve a common goal, namely effective and efficient asset management of the flood defences.

The requirements for a serious game are different. First of all the objectives have to be sufficiently specified. And the game has to be realistic, meaningful and playable. Secondly the desired impact has to be made explicit. Thirdly the potential players has to be known for who the game should play a role in their education or profession. Fourth the conditions for application has to be known, such as the spatial and temporal context.

In the following we close this paper with a short discussion on the innovativeness of serious games, the role of serious games to combine the need for control and dynamic management, and the opportunity to gain capacity building with serious games.

First the innovativeness. Serious games are an emerging means, as presented in section 4 . There are some serious game for flood risk management in the Netherlands which covers small parts of the total figure. However, there is no serious game containing all aspects of complexity presented in section 3 . The hypothetical reasons for this forms part of the challenge for making a game:

- The organisation of flood risk management is divided between several institutions and within the institutions divided between departments. Not many people oversee the field in its entirety. Implementation of new insights or new means demands a long lead time, even in case of evidence. A serious game covering different aspects of complexity to come to a higher level of cooperation would be a new means with potential consequences for organisations way of working, which has to fight its value with perseverance.

- Flood risk managers in the Netherlands are conservative. This is partly historical driven, due to the large flood risks we face. But the conservatism is fostered at present as well. Uncertainty how to handle the complexity, lack of data to use more complex knowledge, and lack of transparency of the benefits of the new opportunities and tools, leads to a behavior of flood risk managers to act conform their experience.

Therefore, serious games are an innovative and emerging tool for flood risk management in the Netherlands.

Secondly the role of serious games to combine the need for control and dynamic management. In the field of asset management the focus is on control. Pretend control is even more important in the world of public infrastructures because the board of the managing institutes is democratic elected. In the field of large infrastructural projects it is accepted not everything is in control. Hertogh \& Westerveld (2010) have developed management strategies for different forms of complexity, as presented in section 3. These strategies are based on "need for control" and "need for interaction" (interaction). For detail complexity it is about meeting the need for control. This concerns the 
need for an overview of a project. To do this, tasks must be split up, which must then be carefully monitored. Related to this is the necessity for the proper collection and storage of data and related decision making. For dynamic complexity, it is about a need for interaction with the (project) environment, both within one's own organization (management, maintenance, reinforcement) and beyond, to deal with external developments proactively. To express the dynamics of the real world in asset management of flood defences, requiring a continuous adaptation to circumstance and adoptation to opportunities, the term adaptive asset management is introduced (den Heijer, 2020; FAIR, 2020). A serious game would be an innovative means to connotate asset management with dynamic respond to opportunities as well.

Finally the capacity building. The employment in the flood risk management sector is of all times and of all ages. In former days the 'experience' was leading for the professional behaviour. Dike management was more or less a guild. Flooding delivered new experience, wry enough. Since the disaster in 1953 a more scientific approach is followed to develop a safer delta. Dikes and large Storm surge barriers have been built. A lot of knowledge and guidelines has been developed. At present universities deliver educated people, and in the profession they are fostered by seniors with several decades of experience applying the more scientific approach. The very experienced people pass along their knowledge and experience. This education-building seems to be robust, but due to the rarity of the flood events this is not tested in reality. In fact, experience is still a large part of our professional behaviour. Let's call it 'informed experience'. The world has changed a lot the past few decades, with more knowledge, more data, more technical and processinnovations, and last but not least the new safety standards, which are beyond the experience. This, together with climate change, and the changing society, asks a lot of the profession for the coming decades with respect to dealing with complexity. Informed experience as the only basis for the professional behaviour is potentially not enough. The education-building has to find new means to develop, value, experience and mainstream new ways for capacity building. The assumption is that when the capability to deal with complexity will increase, the problems and dilemma's with respect to flood defence management can be solved better and the cooperation can come to a higher level. However, experience still has a role. Thus, the upcoming professional behaviour could be referred to as 'experience informed management'. Serious gaming, as an innovative means to capacity building to deal with increasing complexity in flood risk management, may be a part of the transformation to cooperation on a higher level.

\section{References}

1. Aubert, A. H., Medema, W., \& Wals, A. E. J. (2019) Towards a Framework for Designing and Assessing Game-Based Approaches for Sustainable Water Governance, Journal of Water, DOI: $10.3390 /$ w1 1040869
2. Baird, J., Plummer, R., Haug, C., \& Huitema, D. (2014). Learning effects of interactive decisionmaking processes for climate change adaptation. https://doi.org/10.1016/j.gloenvcha.2014.04.019. Elsevier.

3. Barreteau, O., Bousquet, F., \& Attonaty, J. M. (2001). Role-playing games for opening the black box of multi-agent systems: method and lessons of its application to Senegal River Valley irrigated systems. Journal of artificial societies and social simulation, 4(2), 5.

4. Bekebrede, G. (2010). Experiencing complexity: a gaming approach for understanding infrastructure systems (Doctoral dissertation, TU Delft, Delft University of Technology).

5. Bellotti, F., Berta, R., \& De Gloria, A. (2010). Designing effective serious games: opportunities and challenges for research. International Journal of Emerging Technologies in Learning (iJET), 5(SI3), 22-35.

6. Deltacommission. 2008. Samen werken met water, een land dat leeft, bouwt aan zijn toekomst, Findings of the Delta commission (in Dutch).

7. Deltares, 2020. ROBAMCI - Eindrapport, 11201843 (in Dutch)

8. den Haan, R. J., Arevalo, V. J. C., van der Voort, M., \& Hulscher, S. (2016, December). Designing virtual river: A serious gaming environment to collaboratively explore management strategies in river and floodplain maintenance. In International Conference on Games and Learning Alliance (pp. 2434). Springer, Cham.

9. den Heijer, F. (2020). Adaptive flood defence management with ductile dikes, IALCCE, 2020 (submitted).

10. Duijn, M., Immers, L. H., Waaldijk, F. A., \& Stoelhorst, H. J. (2003). Gaming Approach Route 26: a combination of computer simulation, design tools and social interaction. Journal of Artificial Societies and Social Simulation, 6(3).

11. Duke, R. D., \& Geurts, J. (2004). Policy games for strategic management. Rozenberg Publishers.

12. ENW (2017). Fundamentals of Flood protection, Expertise Network for Flood Protection. ISBN/EAN: 978-90-8902-160-1

13. ENW (2017). Advies verticaal zanddicht geotextiel (VZG), ENW-17-13, 18 mei 2017.

14. FAIR (2019). A perspective on the future of asset management for flood protection,. A policy brief from the Interreg North Sea Region FAIR project. https://northsearegion.eu/fair/

15. FAIR, 2020. End report (to be published)

16. HAN (2018). Prometheus, anticiperen op complexiteit bij assetmanagement van dijken via serious gaming, HAN University of applied sciences, 2018.

17. Harteveld, C. (2011). Triadic Game Design: Balancing Reality, Meaning and Play. London: SpringerVerlag.

18. Harteveld, C., \& Bidarra, R. (2007). Learning with games in a professional environment: A case study of a serious game about levee inspection. Proceedings of the 1st learning with games, 555-562. 
19. Hertogh, M., \& Westerveld, E. (2010). Playing with Complexity. Management and organisation of large infrastructure projects.

20. Hummel, H. G., Van Houcke, J., Nadolski, R. J., Van der Hiele, T., Kurvers, H., \& Löhr, A. (2011). Scripted collaboration in serious gaming for complex learning: Effects of multiple perspectives when acquiring water management skills. British Journal of Educational Technology, 42(6), 1029-1041.

21. HWBP (2020). Projectenboek 2020. Hoogwaterbeschermingsprogramma.

Programmabureau 2020.

22. ICID (2004). Man made lowlands. International Commission on Irrigation and Drainage, ISBN 9053451919.

23. ISO. 2014. International Standard ISO 55000, Januari 2014.

24. Johnson, S. (2001). Emergence: The Connected Lives of Ants, Brains, Cities. New York: Scribner. p. 19. ISBN 978-3411040742.

25. Mayer, I. S. (2009). The gaming of policy and the politics of gaming: A review. Simulation \& Gaming, 40(6), 825-862.

26. Meijer, S. (2012). Gaming simulations for railways: Lessons learned from modeling six games for the Dutch infrastructure management. In Infrastructure Design, Signalling and Security in Railway. InTech.

27. Pahl-Wostl, C. (2007). Transitions towards adaptive management of water facing climate and global change. Water resources management, 21(1), 49-62.

28. Rijcken, T., Stijnen, J., \& Slootjes, N. (2012). "SimDelta"-Inquiry into an Internet-Based Interactive Model for Water Infrastructure Development in The Netherlands. Water, 4(2), 295320.

29. RIVM (2004). Risico's in bedijkte termen; een evaluatie van het beleid inzake de veiligheid tegen overstromen (in Dutch), ISBN 90-6960-110-9.

30. ROBAMCI (2015). Werkplan 2015. Geraadpleegd op 22 mei 2018, van http://www.robamci.nl/wpcontent/uploads/2017/12/ROBAMCI_Werkplan2015_definitief_7juli_v2.pdf.

31. Schwandt, D. $\bar{R}$. (2005). When managers become philosophers: Integrating learning with sensemaking. Academy of Management Learning \& Education, 4(2), 176-192.

32. Slager, K. (2003). De ramp. Een reconstructie van de watersnood van 1953. ISBN 9789046702192 (In Dutch).

33. Staatsblad 431 (2016). Wet van 2 november 2016 tot wijziging van de Waterwet en enkele andere wetten (nieuwe normering primaire waterkeringen). Staatsblad van het Koninkrijk der Nederlanden (in Dutch).

34. Staatscourant 234 (2007). Wijziging regeling bijzondere subsidies waterkeren en waterbeheren, Staatscourant van het Koninkrijk der Nederlanden, page 23 (in Dutch).

35. TAW (1997). Safety of flood defences. A new perspective from the TAW Marsroute research programme, Road and Hydraulic Engineering Division, Ministry of Infrastructure and Water management.
36. Van Dantzig D. (1956). Economic decision problems for flood prevention, Econometrica Vol. 24 p 276287.

37. Vissers, M. (2008). Towards a network approach in asset management of hydraulic civil structures, Technical University of Delft, Graduation study.

38. Volker, L., Ligtvoet, A., van den Boomen, M., Wessels, P., van der Lei, T., \& Herder, P. (2013). Asset management maturity in public infrastructure: the case of Rijkswaterstaat. International Journal of Strategic Engineering Asset Management, 1(4), 439453. 